\title{
The Difference of the Actual Price Level from the Equilibrium One and its Impact on Inflation
}

\author{
Ion PARTACHI \\ Vitalie MOTELICA ${ }^{2}$
}

\begin{abstract}
Within the modern monetary policy regimes, the inflationary pressures are, generally, approximated by the excessive demand that generate pressures on the fixed production capacity resulting in a change of prices. This excessive demand is estimated as the deviation of the level of the economic activity, reflected by a series of macroeconomic indicators, from its equilibrium one which is determined using different univariate or multivariate methods. However, an alternative approach which could provide information about the medium term inflationary pressures in an economy is the information about the monetary indicators. In this regard, it is necessary to estimate an equilibrium level of prices which is related to an equilibrium level of production and monetary indicators. Over the medium term, the deviation of the actual level of prices from the equilibrium one will tend to close which will result in inflation. The calculation of the equilibrium level of prices needs to be adjusted in case of a small open economy taking into consideration the macroeconomic indicators of its major trading partners.
\end{abstract}

KEYWORDS: core inflation, inflationary pressures, equilibrium prices, monetary policy, quantity theory of money.

JEL CLASSIFICATION: $C 01, C 22, C 51, E 31, E 51, E 52$

\section{INTRODUCTION}

In line with the best practices in the region, in 2010 National Bank of Moldova started to implement the inflation targeting strategy in order to ensure its primary objective of price stability (http://bnm.md/ro/content/strategia-politicii-monetare-bancii-nationale-moldovei-petermen-mediu). The efficiency of this approach is conditioned on the existence of a modern forecasting and policy analysis system. This represents a suite of tools and procedures which allows to correctly identify the current and predict the future inflationary pressures in order to take the necessary monetary policy actions.

There is a significant effort in understanding the main factors which drive inflation and in developing some efficient tools to analyze and forecast inflation in different economies. One approach that can provide important information on existing inflationary pressures is the model based on the deviation of the current price level from the equilibrium one, the so called P-star model. This is a relatively simple model of inflation dynamics that enables reflecting short-run inflation changes as a process in which the actual price level adjusts to the equilibrium price level, determined in line with the quantity theory of money. It also explains the dynamic link between monetary aggregates and inflation. This framework assumes that there is a long-run

\footnotetext{
${ }^{1}$ Academy of Economic Studies, Modova, ipartachi@gmail.com

${ }^{2}$ Academy of Economic Studies, Moldova, vitalie.d.motelica@gmail.com
} 
equilibrium price level in the economy to which the actual price level tends to converge. The long-run price level is called $\mathrm{P}^{*}$ and the difference between actual price level and the $\mathrm{P}^{*}$ level defines the $\mathrm{P}^{*}$ gap. If the gap is positive, i.e. actual price level is higher than the equilibrium $\mathrm{P}^{*}$ level, one can expect lowering of inflation as the gap tends to close.

This study intends to develop a P-star model for Moldova and to investigate the degree at which it can explain past inflation. Based on the results, it will also state the current and medium term inflationary pressures.

\section{LITERATURE REVIEW}

The P-star indicator was developed in 1998 by Hallman, Porter and Small as a method to assess inflationary pressures for US economy. According to Hallman, Porter and Small (1989), the price gap is a better indicator of inflationary pressure than a series of other criteria. This led to a significant interest in this concept in other countries and as a result, over the years it was developed for other economies as an additional indicator used in policy analysis.

Kool and Tatom (1994) developed a generalized P-star model that accounts for the effects of a big economy on a small open economy with a fixed exchange rate. They tested the P-star model using data from 1960 to 1992 for five small European countries - Austria, Belgium, Denmark, the Netherlands and Switzerland. Most of these countries pegged their currencies to the German mark in that period and they investigated the extent to which prices in those countries have been affected by developments in Germany as well as domestically. Their results confirm the long run link between monetary aggregates and domestic prices for both closed and large, flexible exchange rate as well as for fixed exchange rate countries. In the latter case the long-run equilibrium price level is determined by foreign monetary policy.

In 1998 A. Herrero and M. Pradhan used the P-star model to analyse Spanish prices from 1970 to 1996 adding the foreign price gap to the standard domestic definition of the P-star model (the domestic price gap) to assess the role German price movements played in the inflation in Spain. According to their results, the domestic price gap turned out to be a major explanatory variable for inflation even after the entrance of Spain in the exchange rate mechanism (Herrero and Pradhan, 1998).

A version of the P-star model was developed specifically for the Czech Republic and applied to evaluate the 1991-1999 time series (Frait, Komarek \& Kulhanek, (2000). The results suggest that the dynamics of the Czech inflation evolves in line with the $\mathrm{P}^{*}$ model logic. The inflation in the current period changes to close the price gap. The foreign component of the price gap seems to be more important than domestic one which supports the idea that the equilibrium price level is to a large extent determined by the monetary policy in the EU via the peg Czech currency exchange rate to EUR. The overall results show that inflation in Czech Republic is primarily a monetary phenomenon.

After investigating the monetary indicators of inflation, the properties of the P-star model along with a New-Keynesian-Taylor-type model were analysed by Todter (2002). He also tried to explore a range of monetary policy rules within the P-Star model. He concluded that the price gap is a comprehensive indicator of inflationary pressures, which can play a major role in explaining inflation dynamics as part of an extended Phillips relationship. He also stated that the empirical evidence for the euro area supports the existence of a stable long term money demand and the relevance of the price gap for explaining the development of inflation. 
The P-star model also received some critics. In case of US economy, the P-star model received some critics from Christiano (1989). After, describing the main features of the approach, he questioned the $\mathrm{P}^{*}$ 's ability to predict even dramatic changes in inflation. According to him, $\mathrm{P}^{*}$ is not much better than the other models he used at forecasting inflation from one to three years out.

Given the considerable interest in the topic, this paper intends to explore the development and the role of the P-star indicator for data from Moldova.

\section{P-STAR MODEL METHODOLOGY}

In the process of analysis of the inflationary pressures, it is important to take into account all the available indicators. Generally, central banks during their regular analysis and forecasting exercise, which precedes the monetary policy decision, take into account real economic activity indicators, financial market indicators, commodity prices and monetary aggregates. The P-star model (indicator) offers more information and predictive power than just looking at the change of a specific monetary policy aggregate.

As it was stated above, the P-star model is based on the quantitative theory of money (Scheide, J., Trabandt M. (2000)). It links the short-term changes in current inflation to long-term determinants of the price level. It shows the necessary price level as the economy evolves towards long-run equilibrium and no other disturbances occur.

Information regarding the actual price level is easily accessible from the statistical authority. What makes this approach challenging is the identification of the equilibrium price level, the so-called $\mathrm{P}^{*}$ level. There are two concepts, which take into account domestic or foreign factors. Their share depends on the size and openness of the economy and on the monetary policy regime.

In case of a large and relatively closed economy using a floating exchange rate, the price gap is derived from the following well-known identity

$$
M V=P Y
$$

Where: $\mathrm{M}$ is the amount of money in the economy (e.g. M2), V- the velocity which express how fast the money circulates, P- the actual price level (e.g. CPI) and Y the real output (GDP).

Because long run trends $\mathrm{V}^{*}$ and $\mathrm{Y}^{*}$ are given by the structural characteristics of the economy, the long-run trend of price level $\mathrm{P}^{*}$ can be estimated by:

$$
P^{*}=M V * / Y^{*}
$$

and the domestic $\mathrm{P}^{*}$ gap as:

$$
G A P^{D}=P / P^{*}=\left(Y^{*} / Y\right)\left(V / V^{*}\right)
$$

or in a logarithmic form:

$$
G A P^{D}=p-p^{*}=\left(y^{*}-y\right)+\left(v-v^{*}\right)
$$

where small characters represent natural logarithms. 
The $G A P^{D}$ tends to close over the medium horizon. Based on the theory, there are only two ways how it can happen: (i) by change in the domestic price level (i.e. inflation) or (ii) by change of money stock (i.e. monetary policy decision). The reason, why this concept is important for monetary policy, is that it provides an estimate of underlying pressures to inflation from the actual money stock and allows to adjust the current monetary policy stance to fulfill its objectives. The monetary policy should not eliminate the $G A P^{D}$ automatically if it helps to achieve its objectives, e.g. to decrease inflation. Moreover, the monetary policy can deliberately open the gap to fulfill own objectives. On the other hand, this framework is a medium-term approach and it is not sustainable for the monetary policy to keep the gap open over the long horizons.

The equation (4) offers another explanation for the price $G A P^{D}$ as a combination of the utilization gap $\left(\mathrm{y}^{*}-\mathrm{y}\right)$ and the liquidity gap $\left(\mathrm{v}-\mathrm{v}^{*}\right)$ and represents an overall indicator of inflationary pressures from the real economy and from holding of liquidity. In other words, the price gap denotes the inflation pressures in the economy determined by a too high production capacity utilization or by the monetary overhang, when the velocity of money circulation is below, and liquidity holding above their respective long-run equilibrium. This is the main advantage of the P-star model over other traditional inflationary pressures indicators, which only take into account either the output gap or liquidity gap. Both real factors and monetary factors are considered by the above mentioned model. From the model it can be deducted that when real income and velocity stay at the equilibrium levels, price level moves together with money supply and inflation is a monetary phenomenon.

The P-star model simplicity makes it a good additional tool of assessing inflationary pressures in the economy. Besides that it can indicate that the accumulated effects of monetary policy on money supply are ultimately reflected in the price level. An increase in money supply will influence prices and future inflation when the economy does not operate at its full capacity.

In case of a small open economy which has a fixed exchange rate regime, the domestic money stock is an endogenous variable and the monetary policy cannot influence it actively and as efficient as it was described for a large and relatively closed economy. Because of this, the amount of money fits the actual domestic price level and the $G A P^{D}$ tends to close relatively fast. The medium-term disequilibrium can still exist because of several rigidities or shocks, but is adjusted by endogenous economic mechanisms and mostly by money stock adjustments, not the price level changes. But it doesn't mean that the economy has no anchor for the price level and the long term price level $\mathrm{P}^{*}$ doesn't exist. As can be expected intuitively, the price level is set abroad in the big economy to which the exchange rate is fixed (Pranskeviciute \& Sperberg, 2005). This foreign-based price level can be expressed by following identity:

$$
\begin{aligned}
& P^{D^{*}}=S P^{f^{*}} / Z^{*} \\
& \mathrm{GAP}^{\mathrm{F}}=\mathrm{P}-\mathrm{P}^{\mathrm{D}^{*}}
\end{aligned}
$$

Where: $\mathrm{P}^{\mathrm{d}^{*}}$ is the domestic $\mathrm{P}^{*}$ price level and $\mathrm{GAP}^{\mathrm{F}}$ the respective gap, called as a foreign price gap. S represents a nominal exchange rate, $\mathrm{Z}^{*}$ a real exchange rate trend and $\mathrm{P}^{\mathrm{f}^{*}}$ the trend price level in the foreign economy. It's definition is the same as in the relationship (2). 
The reason we adjust the foreign price level by the nominal and real exchange rate is that the nominal exchange rate just recalculates $\mathrm{P}^{\mathrm{F}^{*}}$, which is denominated in the foreign currency, into domestic one. Exchange rate depreciation causes pressures for domestic inflation to increase and vice versa. The real exchange rate trend trajectory reflects the productivity differential (Balassa-Samuelson effect in particular) between two economies and is mostly driven by the structural characteristics. Because of it, if the economic growth in emerging markets is boosted by fast productivity increases, it can be a source of inflationary pressures in fixed nominal exchange rate regimes.

The $\mathrm{GAP}^{\mathrm{F}}$ exists in the flexible exchange rate regime, too. But it is autonomously closed by exchange rate movement with minimum impact to inflation. Under the fixed exchange rate, the only way is by the inflation growth.

The P-star model can be approximated by an inflation equation in which the inflation rate at period $t_{0}$ is a function of the price gap during the previous period $\mathrm{GAP}_{-1}$ and the inflation rate from the previous period in case of a stationary process.

$$
\pi_{0}=\mathrm{c}+\mathrm{GAP}_{-1}+\pi_{-1}+\xi
$$

where:

$\pi_{0}-$ is the inflation in the current period

$\mathrm{GAP}_{-1}$ - the price gap in the previous period

\section{RESULTS FOR MOLDOVA}

Both approaches to the $\mathrm{P}^{*}$ price level need to be considered for small open countries as Moldova. This is because the exchange rate regime is neither free nor fixed, i.e. the managed floating exchange rate. At the same time, tradable prices are set on the world market and domestic producers can't influence them significantly. Non-tradable are driven by productivity differentials. Furthermore, because of many rigidities and time lags in the transmission mechanism, there is always room for price adjustment based on both gaps.

Following the theoretical concept above, we estimated the domestic $\mathrm{P}^{*}$ price level and the foreign one. The GAP ${ }^{\mathrm{D}}$ is based on the quarterly seasonally adjusted data for the real GDP, M2 and core inflation, where the source for core inflation and real GDP is the National Bureau of Statistics, National Bank of Moldova for M2. Hodrick-Prescott filter was used for detrending the time series. The estimation of the foreign gap $\mathrm{GAP}^{\mathrm{F}}$ is a weighted indicator of Moldova's main trading partners - Eurozone and Russia. Data was obtained from local central banks and statistical offices (CPI, real GDP, M2) and detrended by Hodrick-Prescott algorithm.

The reason we used core inflation instead of CPI inflation is the fact that the latter is more volatile. This is the result of the supply shocks, such as weather conditions and oil price fluctuations which had a severe impact over the years on domestic food prices and fuel prices. This volatility is also determined by the large share of regulated prices (Figure no. 1) which had been adjusted quite often over the sample. 


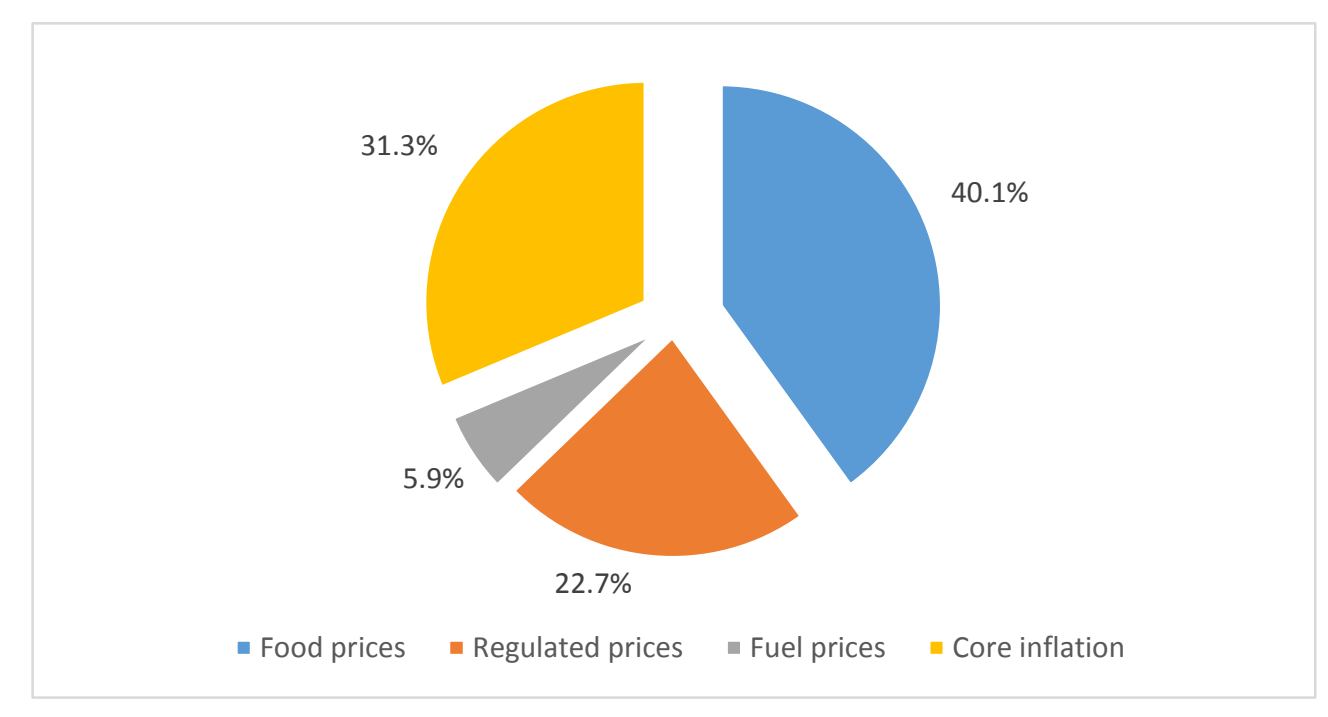

Figure 1. CPI Structure

Source: NBS

The core inflation excludes the food, fuel and regulated prices from headline inflation, it has a more stable dynamics (see the Figure no. 2) and therefore it could better reflect the inflationary pressures coming from the aggregate demand or from the monetary developments.

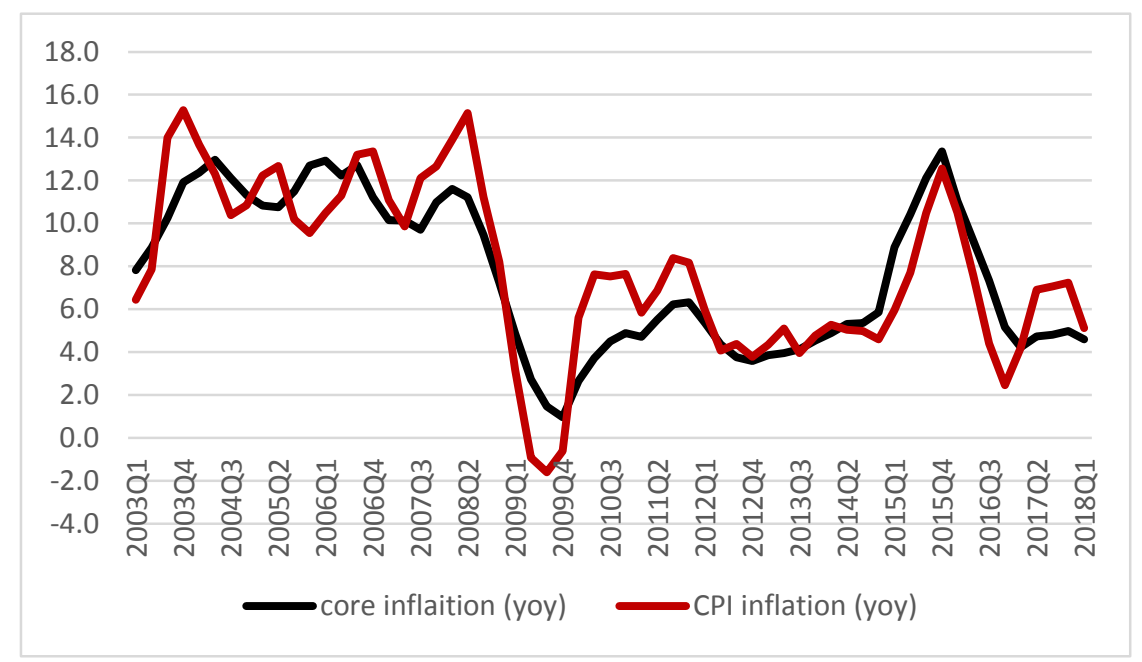

Figure 2. CPI inflation vs. Core Inflation, \% Source: NBS

Figure no. 3 presents the evolution of the domestic gap $\mathrm{GAP}^{\mathrm{D}}$ starting from the 1 st quarter of 2003 till 1st quarter 2018. The positive gap, according to the above mentioned methodology, indicates periods with pressures from monetary developments and an anti-inflationary environment. 


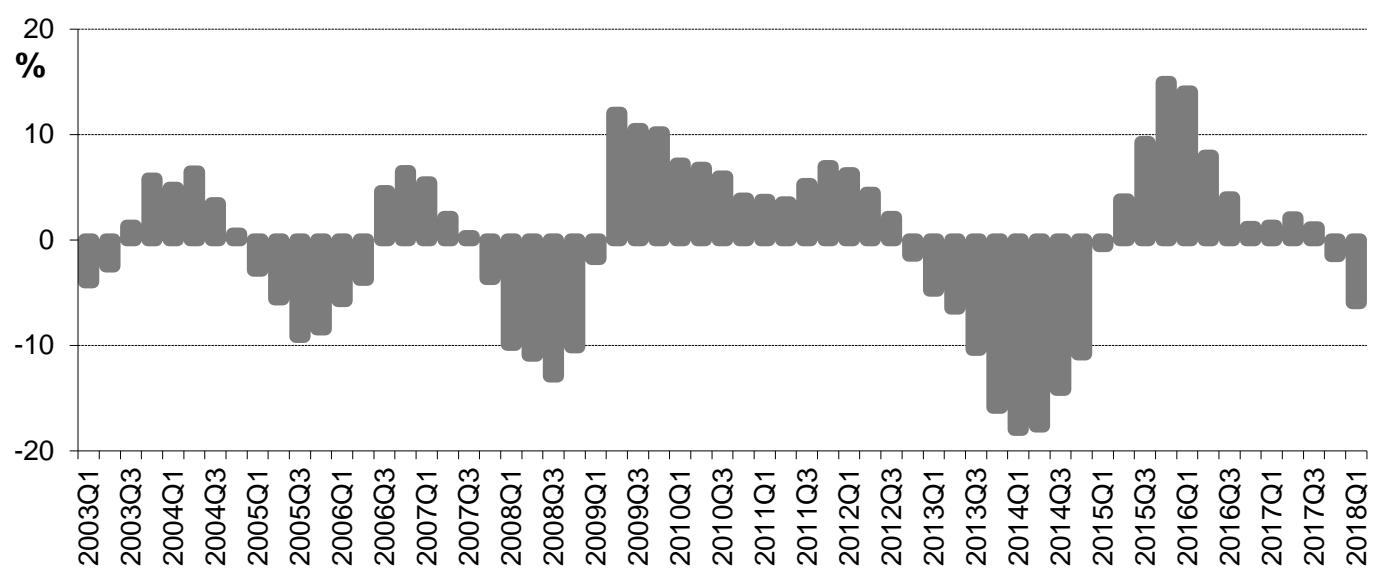

Figure 3 Domestic GAP, \%

Source: Author's calculations

As noted above, given the fact that Moldova is a small open economy, it is reasonable to assume that to a certain extent, the equilibrium price level is determined by foreign factors. Therefore, the foreign based $\mathrm{P}^{*}$ gap is estimated taking into account Moldova's major trading partners, EU and Russia.

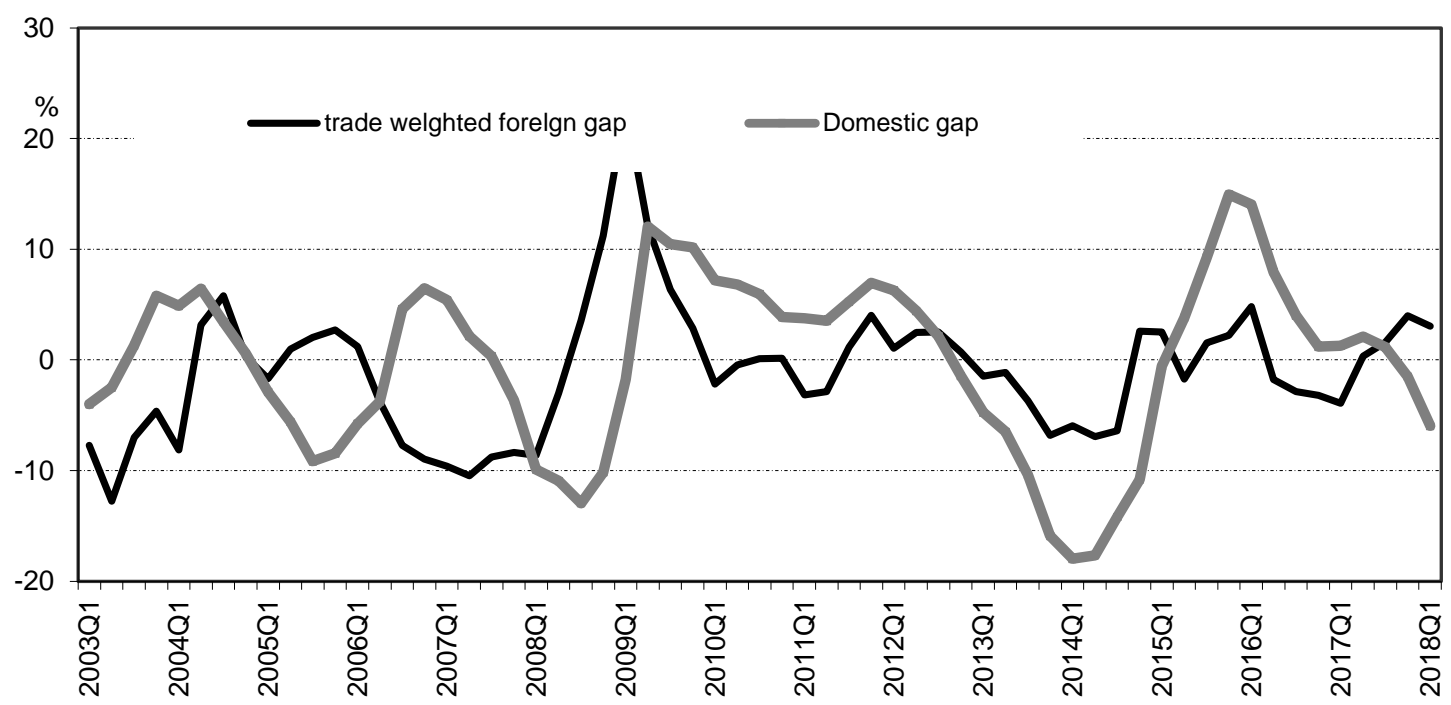

Figure 4. Domestic GAP and Trade Weighted Foreign GAP Source: Author's calculations

So, the figure no. 4 compares the domestic and foreign based $\mathrm{P}^{*}$ gap. It shows that these have different signs and intensities over history. In other words, in some periods there can be strong inflationary pressures from domestic factors while negligible or even disinflationary pressures from foreign factors. Therefore it makes sense to use a combination of the two indicators and to see its behaviour along with the domestic inflation. The information from figure no. 3 and 4 reveals that both gaps were strongly negative in 2014 denoting that the price level was much lower than the equilibrium one. In 2015 there was an increase in the core inflation rate. The positive gaps in 2015 were followed by a sharp disinflation in 2016. One can assume there is a lag between a change of the monetary developments and the respective inflation movements. 
The last observations reveal a mild negative combined gap and, as a result, we could conclude that over the medium term there are some pre-conditions for acceleration of the core inflation. Of course, the link between this GAP indicator and inflation is weakened by many supply shocks, which are common for Moldova. However, one can still depict some important patterns given this data.

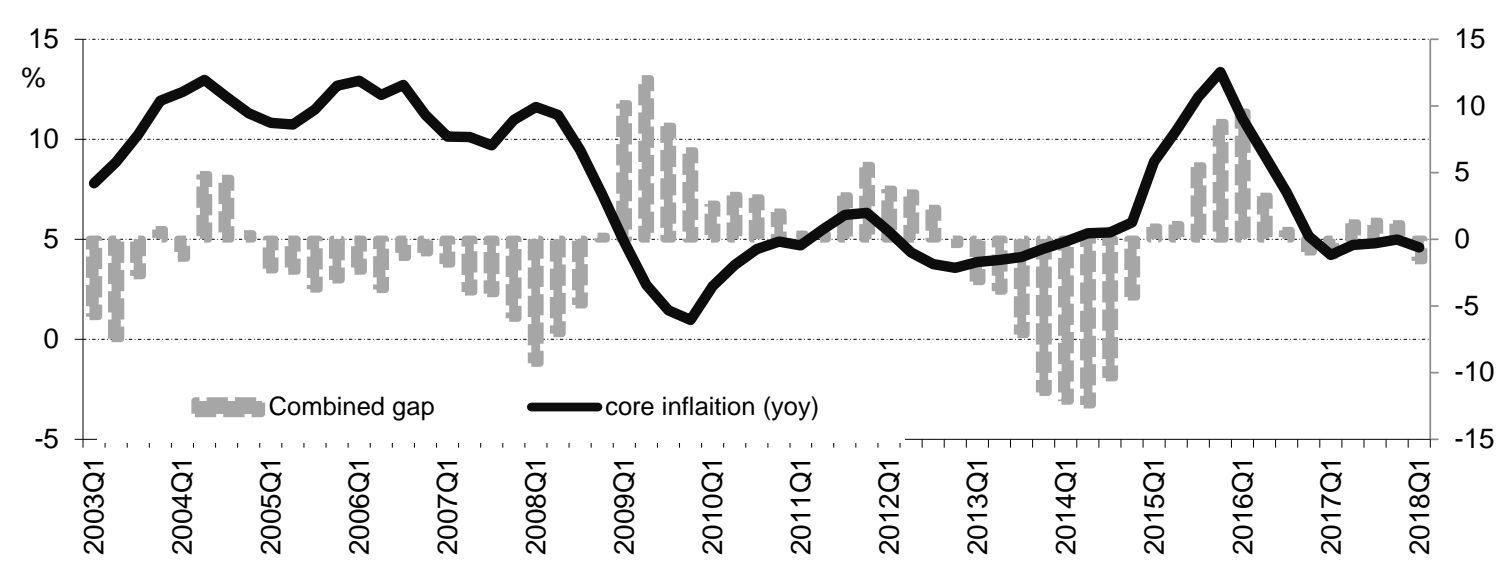

Figure 5. Core Inflation (yoy, \%) and the Combined GAP Source: Author's calculations

To test the significance of the domestic gap, foreign gap and the combined version of them on the core inflation we used the above mentioned simple model described by the equation (1). The results of the estimation are provided in the table below.

Table 1. OLS Estimates for the P-star Model

\begin{tabular}{|l|c|c|c|}
\hline & Domestic GAP & Foreign GAP & Combined GAP \\
\hline & & & $1.97 * *$ \\
\hline const. & $1.20^{* *}$ & $-0.14^{* *}$ & $1.61^{* *}$ \\
\hline GAP(-1) & $-0.1 *$ & $0.65^{* * *}$ & $-0.1^{* *}$ \\
\hline$\pi(-1)$ & $0.77^{* * *}$ & & $0.58^{* * *}$ \\
\hline R2 & & 60 & 58 \\
\hline \multicolumn{2}{|c|}{55} & & \\
\hline Significant at the * $10 \%$ level; $* * 5 \%$ level; $* * * 1 \%$ level & \\
\hline
\end{tabular}

Source: Author's estimations

It turned out that in the given sample the domestic GAP played a relevant role in explaining inflation. At the same time, the price gap which takes into consideration the equilibrium price determined by the relevant variables of Moldova's major trading partners proved to have a more important role in explaining a part of inflation dynamics than the domestic GAP. The coefficient for the foreign gap is statistically significant and has a negative sign which means that a positive gap will determine inflation to fall in the next periods. The table also reveals the results for the model which takes into consideration the combined gap, which is a mix of the domestic and foreign factors. 


\section{CONCLUSIONS}

This article tried to explore an additional approach in assessing inflationary pressures for the medium term horizon. This is important for decision makers in order to be able to adopt the necessary policies in order to ensure price stability. The main objective of this study was to test if the current deviation of the current price level from the equilibrium ones can be used to explain and forecast inflation. After collecting and processing the relevant time series, the conclusion was that both domestic and foreign price gaps contain relevant information about current and future inflation dynamics in Moldova. This result is sustainable with our expectations and with the theoretic assumption that the economic situation in a small open economy such as Moldova is significantly influenced by the economic processes which take place at our major trading partners.

The versions of the GAP which used domestic data and foreign data revealed that the core inflation dynamics in Moldova can be explained to a certain extent by the above mentioned variables. Another important issue which was accomplished within this process was the proof that the short-run dynamics of inflation denotes the features of moving towards long-run equilibrium. The foreign gap model proved to be more efficient in explaining inflation dynamics in Moldova.

The combined gap recorded relatively low negative values during the beginning of this year and therefore it is expected that it will exert a small pro-inflationary influence on the core inflation levels in the medium term. However, given the high base effect from the last year, we expect a decreasing path of headline inflation during 2018 under the assumption that there will not be any severe supply shocks such as a bad harvest or an increase in the oil prices. We believe that the results of this study can be used as an additional tool for forecasting inflation and in the monetary policy decision making process as a relevant source of information regarding the evolution of the price level.

\section{REFERENCES}

Christiano L. (1989). $P^{*}$ : Not the Inflation Forecaster's Holy Grail, Federal Reserve Bank of Minneapolis

Economic bulletin (2018), No. 3, http://www.ecb.europa.eu/pub/economic-bulletin/html/index. en.html

Frait J., Komarek L, Kulhanek L. (2000). P-star-model based analysis of inflation dynamics in the Czech Republic, Working Paper. Coventry: University of Warwick, Department of Economics. Warwick economic research papers (No.565)

Hallman, J.J., Porter, R.D. and Small, D. H. (1989). M2 per Unit of Potential GNP as an Anchor for the Price Level, Staff Studies 157, Board of Governor of Federal Reserve System

Herrero A., Pradhan M. (1998). The Domestic and Foreign Price Gaps in the P-star Model: Evidence from Spain

Kool C., Tatom J. (1994). The P-star Model in Five Small Economies, Federal Reserve Bank of St. Louis Review, 11-29

National Bureau of Statistics of the Republic of Moldova (NBS), http://www.statistica.md/

Pranskeviciute, J. and Sperberg, A. (2005). An investigation into the dynamics of inflation in Latvia: The P-star approach, SSE Riga Working Papers, (10), URL http://www.sseriga.edu.lv/ library/working_papers/ FT_2005_10.pdf

Scheide, J., Trabandt M. (2000). Predicting inflation in Euroland - the P-star approach, Kiel Institute of World Economics

Todter, K.H. (2002). Monetary indicators and policy rules in the P-star model, Economic Research Centre of the Deutsche Bundesbank 